\title{
Lung function change in hyperbaric chamber inside attendants
}

\section{Peachapong Poolpol ${ }^{1,2}$, Pornchai Sithisarankul ${ }^{2}$, Thanapoom Rattananupong ${ }^{2}$}

\author{
${ }^{1}$ Maritime Medicine Residency Training Institute, Naval Medical Department, Royal Thai Navy, Bangkok, Thailand \\ ${ }^{2}$ Department of Preventive and Social Medicine, Faculty of Medicine, Chulalongkorn University, Bangkok, Thailand
}

\begin{abstract}
Background: Hyperbaric oxygen therapy is one of new trends of additional treatment, especially for non-diving-related diseases in Thailand. Hyperbaric inside attendants have to work under hyperbaric environment to provide medical care for patients in the hyperbaric chamber. This study aims to investigate longitudinal change in lung function in hyperbaric inside attendants (HIAs) and the relationship with hyperbaric exposure. Materials and methods: This is a retrospective longitudinal study exploring the adverse long-term effects to the lungs in HIAs. All inside attendants (HIAs) who worked in the public hospitals or medical centres with multiplace hyperbaric chamber in Thailand were included. To be considered for inclusion in the study, inside attendants were required to have at least two follow-up lung function tests and minimum 1-year interval at baseline from annually periodic examination. Lung function of HIAs were compared against reference values of the Thai population. Results: There were 51 subjects with 9.26-year mean period of follow-up. The HIAs showed a significantly decrease in measured lung function in average forced expiratory volume in 1 second $\left(F E V_{1}\right)$, forced expiratory flow at $25-75 \%$ of functional vital capacity $\left(F E F_{25-75 \%}\right)$ and $F E V_{1} / F V C$ ratio over time. The annual reductions in $F E V_{1}, F E F_{25-75 \%}$ and $F E V_{1} / F V C$ ratio were $22.52 \mathrm{~mL}$ per year, $44.92 \mathrm{~mL} / \mathrm{s}$ per year and $0.48 \%$ per year, respectively. The study showed significant differences in annual changes in $F V C, F E F_{25-75 \%}$ and $F E V_{1} / F V C$ ratio between HIAs and the lung function predicted values for the Thais. However, the results revealed no differences of annual change in $\mathrm{FEV}_{1}$ from predicted values. The average working depths, average session duration and total working hours as HIAs were related with the changes of lung function. Conclusions: Working in a hyperbaric environment does affect the lung function of HIAs. In addition to fitness to work implementation, periodic lung function evaluation should be encouraged to monitor further possible harm to the attendants.
\end{abstract}

(Int Marit Health 2019; 70, 2: 125-131)

Key words: lung function, pulmonary function, hyperbaric inside attendant, hyperbaric chambers, hyperbaric attendant

\section{INTRODUCTION}

Hyperbaric oxygen therapy (HBOT) treatment is a procedure performed inside a pressurised chamber (the Hyperbaric Chamber). The patient is placed inside the chamber and the internal pressure is increased to a specific treatment level above 1 absolute atmospheric pressure The patient breathes $100 \%$ oxygen for the duration of the treatment.
While most commonly associated with diving-related conditions, HBOT is also an effective treatment in a number of non-diving related conditions such as delayed radiation injury (soft tissue and bone necrosis) and arterial insufficiencies. In Thailand, HBOT is becoming an increasingly common method of treatment for such conditions.

The hyperbaric chamber can be categorised in two types, the monoplace hyperbaric chamber and the multiplace 
hyperbaric chamber. With the multiplace hyperbaric chamber, a hyperbaric inside attendant (HIA) is stationed inside the chamber to provide medical care for patients and take action in case of emergencies during treatment.

Although the HIA is inside the hyperbaric chamber, they do not breathe $100 \%$ oxygen like the patients. They breathe the pressurised air within the chamber and therefore have the potential to experience decompression sickness and the associated harmful effects that can have on the various organs and systems of the body. Exposure to the hyperbaric environment also challenges pulmonary function beyond normal physiology. HIAs are exposed to an increased partial pressure of oxygen and the risk of gas microemboli forming during their session in the hyperbaric chamber. High oxygen partial pressure exposure may increase the oxidative stress, inducing inflammatory processes within the respiratory system [1]. During decompression, gas microemboli released from nitrogen saturated tissues are transferred to the lungs to be eliminated by exhalation. These microemboli can cause pulmonary microvasculature inflammation, gas exchange impairment and transient pulmonary hypertension [2, 3]. During breathing compressed air in the hyperbaric environment, the effort of breathing and airway resistance will increase, while lung compliance will decrease. These may affect the respiratory function, especially airway function $[4,5]$. Airway obstruction is a relative contraindication for working in pressurised environments because pulmonary over inflation syndrome caused by pulmonary barotrauma is a serious, potentially fatal condition if it occurs during decompression. Therefore, healthy pulmonary function is one of the important elements for HIAs to be declared fit for duty.

In Thailand, Navy divers and HIAs are required to have pre-placement and annual periodic examinations, which include spirometry to detect any abnormality in lung function, in order to ensure that they are fit to work. Currently, there is only one study on lung function change in HIAs [6] and a few studies involving commercial divers [7-21], all with inconclusive patterns of lung function change in these populations. This study aims to investigate longitudinal change on lung function in HIAs in Thailand from the outset of their careers until present day, and with relation to hyperbaric exposure.

\section{MATERIALS AND METHODS}

This is a retrospective longitudinal study on lung function change in HIAs. The total number of HIAs who had worked in facilities with multiplace hyperbaric chambers in public hospitals in Thailand is 63. The group consisted of 20 HIAs from Underwater and Aviation Medicine Division, Naval Medical Department, Royal Thai Navy, 8 HIAs from Centre of Hyperbaric Medicine, Somdech Phra Pinklao Hospital, 12 HIAs from Underwater and Hyperbaric Medical Centre,
Queen Sirikit Naval Hospital, 17 HIAs from Underwater and Aviation Medicine Division, Abhakornkiatiwong Hospital and 6 HIAs from Division of Underwater and Hyperbaric Medicine, Vachiraphuket Hospital.

The inclusion criteria were HIAs who were at least 20 years old at the start of their careers, had a minimum of 1-year practical experience as an HIA and who had a pre-placement Pulmonary Function Test (PFT), as well as at least one follow up PFT performed at least 12 months later. HIAs meeting these criteria were eligible for inclusion regardless of whether they were still actively working, were no longer employed as HIAs or were retired.

Spirometric data, age and height from each examination were collected from the medical records of HIAs who attended for pre-service and annual medical examinations. The data collection range covered the period from beginning their career as an HIA up until June 30, 2018. Data was collected at the assigned medical centre consisting of the Underwater and Aviation Medicine Division, Naval Medical Department, the Underwater and Aviation Medicine Division, Abhakornkiatiwong Hospital and the Vachiraphuket Hospital.

The HIAs' age and height were recorded, and spirometry was performed at the medical centres. HIAs were required to have a pre-service examination and an annual medical assessment to be declared "fit to work" in a hyperbaric chamber. Pre-service spirometry was collected as a baseline value. Annual spirometry was recorded in the record form. Spirometry was performed according to standard operating procedure by certified technicians. The spirometer was regularly calibrated before use, in accordance with the manufacturers' recommendations.

Hyperbaric inside attendants completed an anonymous questionnaire providing their information at the date of answering the questionnaire on current workplace, age, height, weight, smoking history, medical history, underwater activities (recreational diving and operational diving history) and work experience in hyperbaric chambers (total years of working, total number of working, average working depth, maximum working depth, average session duration and total hours of working).

The following lung function parameters were measured: forced vital capacity (FVC, $\mathrm{mL}$ ), forced expiratory volume in 1 second $\left(\mathrm{FEV}_{1}, \mathrm{~mL}\right)$ and forced expiratory flow at $25-75 \%$ of FVC $\left(\mathrm{FEF}_{25-75 \%}, \mathrm{~mL} / \mathrm{s}\right)$. The $\mathrm{FEV}_{1} / \mathrm{FVC}$ ratio $\left(\mathrm{FEV}_{1} \%\right)$ was calculated. All values were adjusted to the percentage of predicted values based on the Dejsomrirutai's reference spirometric values for healthy lifetime nonsmokers in Thailand [22] except $\mathrm{FEV}_{1} \%$ was not expressed as percentages.

\section{STATISTICAL ANALYSIS}

Data analysis was performed using STATA version 15.0 (StataCorp. 2017. Stata Statistical Software: Release 15. 


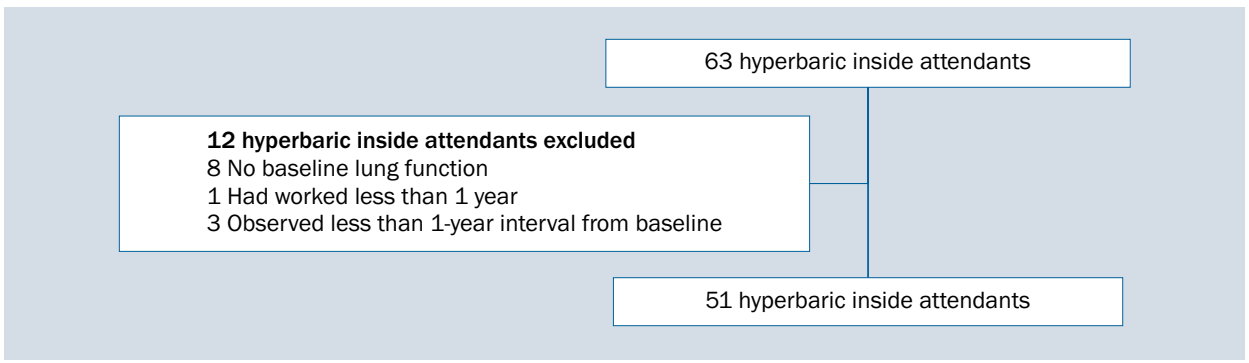

Figure 1. Flow chart of subjects inclusion and exclusion

College Station, TX: StataCorp LLC). The variables that had normal distribution were presented as mean \pm standard deviation (SD) and those that did not have normal distribution were presented as median (interquartile range [IQR]). The qualitative variables were expressed in number and percentage. Mixed model was used to evaluate the change in lung function parameters over time and comparison with the change of sex-, age- and height-matched predicted values. The relationship between change on lung function parameters over time and associated factors of hyperbaric exposure were tested by mixed model ( $p$-value $<0.25$ was considered for inclusion in the model). The chosen approach was the random intercept, random slope method with an unstructured covariance matrix. The level of statistical significance was set to be 0.05 .

The study was approved by the Institutional Review Board of Faculty of Medicine, Chulalongkorn University, the Research Ethics Committee of the Naval Medical Department (NMD-REC) and the Vachiraphuket Hospital Research Ethics Committee (VPHREC).

\section{RESULTS}

Fifty-one HIAs (81\%) satisfied the inclusion criteria (Fig. 1). Eight subjects who had no available pre-service lung function test, 1 who worked less than 1 year and 3 subjects who had at least 2 follow-ups but less than 1-year interval from baseline were not included in the study. Forty-four (86.27\%) subjects were male. At the initial pre-service examination, the mean (SD) age was 30.86 (4.78) years. The mean (SD) follow-up time was 9.26 (5.78) years. The minimum follow-up time was 1.5 year and the maximum follow-up time was 23.3 years. The mean (SD) number of follow-ups was 8.06 (3.82).

At the date of answering the questionnaire, the HIAs had a mean (SD) height of $169.39(6.16) \mathrm{cm}$, a mean (SD) weight of 67.85 (8.67) $\mathrm{kg}$ and a mean (SD) body mass index of 23.63 $(2.29) \mathrm{kg} / \mathrm{cm}^{2}$. Thirty-three (66\%) were non-smokers, $8(16 \%)$ were previous smokers and $9(18 \%)$ were current smokers. Only $10(20 \%)$ had previous medical illness including hypertension, dyslipidaemia, atrial fibrillation, central nervous system lymphoma, gout, polycythaemia, dry eye, glaucoma and allergic rhinitis. None of the subjects had chronic lung diseases or history of chest or upper abdomen surgery.

There were 33 (68.75\%) HIAs who had operational diving history and $45(90 \%)$ had recreational diving experience with a median (IQR) of $13(11.5,2-1,000)$ total number of recreational dives. An average (SD) diving depth was 59.09 (25.06) feet sea water (fsw). The mean (SD) maximum depth was 93.09 (31.96) fsw.

While working in multiplace hyperbaric facilities, HIAs had an average 10.08 years of working in total (SD 6.31). The median (IQR) number of sessions was 300 (395). They accumulated a median of 500 working hours in multiplace hyperbaric chambers (IQR 570). The mean (SD) of working hours in each session was $1.70(0.34)$ hours. Forty-seven (95.92\%) subjects had an average working depth at $45 \mathrm{fsw}$, while only $2(4.08 \%)$ had an average working depth at 60 fsw. There were 27 (56.25\%), 12 (25\%) and 7 (14.58\%) HIAs who had the maximum working depth at 165,112 and $60 \mathrm{fsw}$, respectively. The other $2(4.16 \%)$ subjects had a maximum working depth at 45 and 120 fsw. The demographic data and working history in multiplace hyperbaric chambers are shown in Table 1.

The baseline lung function parameters of HIAs are show in Table 2. At the baseline, the mean (SD) actual $\mathrm{FEV}_{1}$ was $3,747.45(666.17) \mathrm{mL}$, mean (SD) actual FVC was 4,373.53 (814.67) $\mathrm{mL}$, mean (SD) absolute $\mathrm{FEF}_{25-75 \%}$ was 4287.50 (1190.81) $\mathrm{mL} / \mathrm{s}$ and mean (SD) $\mathrm{FEV}_{1} \%$ was $86.06 \%$ (6.05). When expressed as a percentage of predicted, the mean (SD) $\mathrm{FEV}_{1}$ was 110.38 (13.68) \% of predicted, mean (SD) FVC was 108.22 (13.99) \% of predicted and mean (SD) $\mathrm{FEF}_{25-75 \%}$ was 100.17 (24.29) \% of predicted.

Annual changes in lung function parameters are shown in Table 3. The change of actual lung function parameters after adjusting for sex, pre-service age, height and smoking history showed that $\mathrm{FEV}_{1}, \mathrm{FEF}_{25-25 \%}$ and $\mathrm{FEV}_{1} \%$ significantly decreased over time, while there was no significant change in FVC. However, the comparison of actual lung function change in HIAs and the predicted values showed that there was a different change in $\mathrm{FVC}, \mathrm{FEF}_{25-75 \%}$ and $\mathrm{FEV}_{1} \%$, while there was no difference in the reduction in $\mathrm{FEV}_{1}$ over time. The annual reduction over time in $\mathrm{FEV}_{1}$ in the HIAs group 
was similar to the predicted value. The predicted value of FVC significantly decreased but in the HIAs group did not change. The decrease in $\mathrm{FEF}_{25-75 \%}$ and $\mathrm{FEV}_{1} \%$ were significantly greater in HIAs compared with the predicted values. Comparison of the changes in lung function between

Table 1. Demographic data and working history in multiplace hyperbaric chambers $(n=51)$

\begin{tabular}{|c|c|}
\hline & $\begin{array}{l}\text { Mean } \pm \text { SD; } \\
\text { Number }(\%)\end{array}$ \\
\hline Male & $44(86.27 \%)$ \\
\hline Age [years] & $30.86 \pm 4.78$ \\
\hline Follow-up time [years] & $9.26 \pm 5.78$ \\
\hline Number of follow-ups & $8.06 \pm 3.82$ \\
\hline Height $[\mathrm{cm}]$ & $169.39 \pm 6.16$ \\
\hline Weight [kg] $(n=50)$ & $67.85 \pm 8.67$ \\
\hline BMI $\left[\mathrm{kg} / \mathrm{cm}^{2}\right](\mathrm{n}=50)$ & $23.63 \pm 2.29$ \\
\hline $\begin{array}{l}\text { Smoking history }(n=50) \text { : } \\
\text { Non-smoker } \\
\text { Ex-smoker } \\
\text { Current smoker }\end{array}$ & $\begin{array}{l}33(66 \%) \\
8(16 \%) \\
9(18 \%)\end{array}$ \\
\hline Operation diving history $(n=48)$ & $33(68.75 \%)$ \\
\hline $\begin{array}{l}\text { Recreational diving history }(n=50) \text { : } \\
\text { Total no. of dives, median (IQR) }(n=44) \\
\text { Average depth [fsw] }(n=43) \\
\text { Maximum depth [fsw] }(n=43)\end{array}$ & $\begin{array}{l}45(90.00 \%) \\
13(11.5) \\
59.09 \pm 25.06 \\
93.09 \pm 31.96\end{array}$ \\
\hline Total years of working & $10.08 \pm 6.31$ \\
\hline Total no. of session, median (IQR) $(n=48)$ & $300(395)$ \\
\hline $\begin{array}{l}\text { Average working depth }(n=49) \text { : } \\
45 \mathrm{fsw} \\
60 \mathrm{fsw}\end{array}$ & $\begin{array}{l}47(95.92 \%) \\
2(4.08 \%)\end{array}$ \\
\hline $\begin{array}{l}\text { Maximum working depth }(n=48) \text { : } \\
45 \mathrm{fsw} \\
60 \mathrm{fsw} \\
112 \mathrm{fsw} \\
120 \mathrm{fsw} \\
165 \mathrm{fsw}\end{array}$ & $\begin{array}{l}1(2.08 \%) \\
7(14.58 \%) \\
12(25.00 \%) \\
1(2.08 \%) \\
27(56.25 \%)\end{array}$ \\
\hline Average session duration $(n=47)$ & $1.70 \pm 0.34$ \\
\hline Total working hour, median (IQR), $(n=45)$ & $500(570)$ \\
\hline
\end{tabular}

HIAs and the predicted values is shown in Table 4. When considering the change in lung function as a percentage of the predicted values, there was no change in $\mathrm{FEV}_{1}$, FVC and $\mathrm{FEF}_{25-75 \%}$.

There were only three hyperbaric exposures associating with lung function change over time consisting of average working depth, average session duration and total hours of working in hyperbaric chamber. The total number of working hours was also correlated with lung function change over time, but there was statistical collinearity with total hours of working, so the total hour of working was used for calculation in the model. There was a significant positive relationship between the change in actual $\mathrm{FEV}_{1}$ and average working depth. Total hours of working were significantly positively correlated with a change in $\mathrm{FEV}_{1} \%$. However, changes in actual FVC and percentage of predicted FVC were negatively correlated with total hours of working. The change in percentage of predicted $\mathrm{FEV}_{1}$ was a significant positive relationship with average working depth and a negative relationship with average session duration. However, there was no hyperbaric exposure associated with change in actual $\mathrm{FEF}_{25-75 \%}$ and percentage of predicted $\mathrm{FEF}_{25-75 \% \text {. }}$

Table 3. Annual changes in lung function in hyperbaric inside attendants

\begin{tabular}{|c|c|c|}
\hline & $\begin{array}{l}\text { Changes } \\
\text { in actual values }{ }^{a} \\
\text { Mean }(95 \% \mathrm{CI})\end{array}$ & $\begin{array}{l}\text { Changes } \\
\text { in percentage } \\
\text { of predicted }^{\mathrm{a}} \\
\text { Mean }(95 \% \mathrm{Cl})\end{array}$ \\
\hline $\mathrm{FEV}_{1}[\mathrm{~mL} /$ year, \%/year $]$ & $\begin{array}{l}-22.52^{\dagger} \\
(-34.07,-10.97)\end{array}$ & $\begin{array}{l}+0.004 \\
(-0.35,+0.36)\end{array}$ \\
\hline FVC [mL/year, \%/year] & $\begin{array}{l}-8.81 \\
(-27.12,+9.51)\end{array}$ & $\begin{array}{l}+0.25 \\
(-0.19,+0.70)\end{array}$ \\
\hline $\begin{array}{l}\mathrm{FEF}_{25-75 \%}[\mathrm{~mL} / \\
/ \mathrm{s} \text {-year, \%/year] }\end{array}$ & $\begin{array}{l}-44.92^{\dagger} \\
(-66.34,-23.50)\end{array}$ & $\begin{array}{l}-0.36 \\
(-0.95,+0.22)\end{array}$ \\
\hline $\mathrm{FEV}_{1} \%[\% /$ year $]$ & $\begin{array}{l}-0.48^{\dagger} \\
(-0.63,0.34)\end{array}$ & \\
\hline
\end{tabular}

Table 2. Baseline lung function in hyperbaric inside attendants

\begin{tabular}{|c|c|c|}
\hline & $\begin{array}{l}\text { Actual values }(n=51) \\
\text { Mean } \pm \text { SD }\end{array}$ & $\begin{array}{l}\text { Percentage of predicted }(n=51) \\
\text { Mean } \pm \text { SD }\end{array}$ \\
\hline $\mathrm{FEV}_{1}$ & $3,747.45 \pm 666.17 \mathrm{~mL}$ & $110.38 \pm 13.68 \%$ \\
\hline FVC & $4,373.53 \pm 814.67 \mathrm{~mL}$ & $108.22 \pm 13.99 \%$ \\
\hline $\mathrm{FEF}_{25-75 \%}(n=28)$ & $4,287.50 \pm 1,190.81 \mathrm{~mL} / \mathrm{s}$ & $100.17 \pm 24.29 \%$ \\
\hline $\mathrm{FEV}_{1} \%$ & $86.06 \pm 6.05 \%$ & \\
\hline
\end{tabular}


Table 4. Comparison of changes in lung function in hyperbaric inside attendants and reference values

\begin{tabular}{|c|c|c|c|}
\hline & $\begin{array}{l}\text { Changes in actual values }{ }^{a} \\
\text { Mean }(95 \% \mathrm{Cl})\end{array}$ & $\begin{array}{l}\text { Changes in reference values }{ }^{a, b} \\
\text { Mean }(95 \% \mathrm{Cl})\end{array}$ & $\mathbf{P}$ \\
\hline $\mathrm{FEV}_{1}[\mathrm{~mL} /$ year $]$ & $-22.52^{\dagger}(-34.07,-10.97)$ & $-20.36^{\dagger}(-21.77,-18.27)$ & 0.65 \\
\hline FVC [mL/year] & $-8.81(-27.12,+9.51)$ & $-14.72^{\dagger}(-15.96,-13.47)$ & 0.01 \\
\hline $\mathrm{FEF}_{25-75 \%}[\mathrm{~mL} / \mathrm{s}$-year $]$ & $-44.92^{\dagger}(-66.34,-23.50)$ & $-34.73^{\dagger}(-36.45,-33.01)$ & $<0.001$ \\
\hline $\mathrm{FEV}_{1} \%[\mathrm{~mL} /$ year $]$ & $-0.48^{\dagger}(-0.63,-0.34)$ & $-0.21^{\dagger}(-0.21,-0.20)$ & $<0.001$ \\
\hline
\end{tabular}

\section{DISCUSSION}

This is a study exploring adverse long-term effects on the lung in hyperbaric chamber inside attendants. During hyperbaric oxygen therapy, hyperbaric chamber inside attendant have to stay under the same pressure as patients. However, while patients breathe $100 \%$ oxygen, HIAs breathe pressurised air for almost the entire session, an experience similar to that of scuba divers breathing from a cylinder compressed air. HIAs are exposed to the hyperbaric environment as long as they remain active in the field of HBOT, while patient treatments number in the range of 40-50 sessions. So, the discussion on results is limited to comparing with studies on hyperbaric inside attendants and commercial divers who breathe pressurised air during the course of their work.

The first point of interest relates to the value of the baseline of FVC. The percentage of predicted FVC in this study was $108.22 \%$. Base on this data, we could infer that HIAs have larger lung than predicted. This finding is similar to other studies indicating that divers have a larger lung capacity than the normal population $[7,9-12,16]$. In addition, this result supports the idea that larger lung capacity in hyperbaric exposed workers is part of natural selection because our subjects had larger lung capacities since starting their career. Similarly, the study of Adir et al. [15] showed that there was no different in FVC between experienced and inexperienced divers with high lung capacity. In the same way, a study carried out by Skogstad et al. [12] showed there was no significant difference in vital capacity between diving students who had previous diving experiences and those who didn't. Both subgroups had more than $100 \%$ of predicted FVC at baseline.

Only one study about pulmonary function in inside attendants was a cohort study of Ozdemir et al. [6] It was a study of lung function over 1 year of 11 inside attendants compared with a matched control group of 15 . They found that $\mathrm{FEV}_{1} \%$, percentage of predicted $\mathrm{FEV}_{1}$ and $\mathrm{FEF}_{25-75 \%}$ in HIAs significantly declined in $2.3 \%, 3.7 \%$ and $6.9 \%$ over a year, respectively. However, there was no difference when compared with the control group. This study believed that shallow diving depth in the HIAs group is the reason why there was no difference from the control group. This contrasted with the findings in our study. We showed that there was no change in percentage of predicted for $\mathrm{FEV}_{1}, \mathrm{FVC}$ and $\mathrm{FEF}_{25-75 \%}$ but there was a significant decrease of $0.48 \%$ per year of $\mathrm{FEV}_{1} \%$. Additionally, there were significant differences in changes of actual FVC, $\mathrm{FEF}_{25-75 \%}$ and $\mathrm{FEV}_{1} \%$, when we compared actual lung function changes in HIAs and the predicted values. A reason that changes in the percentage of predicted values for $\mathrm{FEV}_{1}, \mathrm{FEF}_{25-75 \%}$ and $\mathrm{FEV}_{1} \%$ were different from our study may be a fewer average number of sessions in our study. The average number of sessions in our study was 29.76 per year while the average in this study was 71.5 sessions per year. Another possible reason may be the relatively small number of inside attendants in this study resulted in higher variance in the pattern of lung function change. However, shallow diving depth might not be the main reason because average depths in both studies were similar.

In this study, there was no change in FVC over time (non-significant $8.81 \mathrm{~mL}$ per year reduction). Some studies supported our results that there was no change in FVC over time [12, 20]. However, a decrease in FVC among divers has been reported previously [8-10, 13, 17], with only two studies reporting FVC increase [14, 21]. Voortman et al. [21] analysed pulmonary function in 1,260 navy divers and found an increase in inspiratory vital capacity around $73 \mathrm{~mL} /$ year. It could be concluded that an increase in vital capacity was due to diving and training. Even if there was no increase in vital capacity in our study, there was still no decrease over time while the predicted value significantly decreased. Our hypothesis was that HIAs had adapted to hyperbaric exposure, but this effect was not strong enough to defeat natural deterioration due to the effects of aging. This is a reason why there was no change in FVC overtime but there was a difference in the change of FVC between HIAs and predicted values. In contrast with the study of Skogstad et al. [13], there was a greater reduction in FVC in divers than the control group. When expressed as a percentage of predicted, there was no significant reduction in 
FVC. The result was similar to the study of Ozdemir et al. [6] as mentioned above. Almost all studies in divers found that the percentage of predicted FVC declined $[9,19]$ whereas Chong et al. [18] reported that percentage of predicted FVC in 116 Navy divers significantly increased over 5 years.

A change in $\mathrm{FEV}_{1}$ in HIAs was similar to other studies in commercial divers $[9,10,12,13,16,17]$. Previous studies, such as those of Tetzlaff et al. [16] and Skogstad et al. [13] that had control groups in their studies, showed the different results in comparison of $\mathrm{FEV}_{1}$ change. A longitudinal cohort study of Skogstad et al. [13] found that there was a significant difference in change of $\mathrm{FEV}_{1}$ over a 6 years follow-up period between 77 commercial divers and 64 non-smoking and non-diving policemen. $\mathrm{FEV}_{1}$ in divers showed a greater reduction than the control group. This was in contrast to Tetzlaff et al. [16] and our study. In our study, there was no difference in $\mathrm{FEV}_{1}$ reduction in HIAs from predicted value. The results were similar to Tetzlaff et al. [16] study that found decline of $\mathrm{FEV}_{1}$ after 5 years observation in 468 male military scuba divers was no difference from decline of $\mathrm{FEV}_{1}$ in 122 submariner. However, the pattern of change in the percentage of predicted FEV ${ }_{1}$ couldn't be concluded in divers to be the same as with inside attendants. In our study, there was no change in percentage of predicted in $\mathrm{FEV}_{1}$ but there was significant reduction in percentage of predicted in $\mathrm{FEV}_{1}$ in the previous study in inside attendant [6]. The studies in divers reported either no change [9], increase [18] or decrease $[9,19]$ in percentage of predicted in $\mathrm{FEV}_{1}$. Even if it was in the same study, it may show different results of reduction in $\mathrm{FEV}_{1}$ such as a study reported by Watt [9] which observed two group of commercial divers. Although a group of 224 commercial divers that was observed for a 3-4 year period showed a reduction of actual $\mathrm{FEV}_{1}$ but no change in percentage predicted of $\mathrm{FEV}_{1}$, a group of 123 commercial divers that was observed for over 5 years showed both decline of actual $\mathrm{FEV}_{1}$ and percentage predicted of $\mathrm{FEV}_{1}$.

The HIAs also showed a loss in $\mathrm{FEF}_{25-75 \%}$ over time without any association to hyperbaric exposure factors. Normally, change in mid forced expiratory flow varied according to vital capacity so $\mathrm{FEF}_{25-75 \%}$ was not included in the criteria to be declared fit to dive. So many studies did not observe this value in their studies. However, the studies that reported $\mathrm{FEF}_{25-75 \%}$ as a parameter found a decline of FEF $_{25-75 \%}$ in every study [10,12, 13, 17, 21]. We compared change of $\mathrm{FEF}_{25-75 \%}$ in HIAs and predicted values. We found that there was a greater decrease in HIAs than the predicted values. By contrast, Skogstad et al. [13] reported that no difference in decline between divers and the control group. Focusing on percentage of predicted, there was also no change in $\mathrm{FEF}_{25-75 \%}$ as other parameters.

$A$ reduction in $\mathrm{FEV}_{1} / \mathrm{FVC}$ percentage $\left(\mathrm{FEV}_{1} \%\right.$ ) was one of the concerns when deciding fitness for work in a hyperbaric environment because low $\mathrm{FEV}_{1} \%$ indicated airway obstruction that may be a risk for pulmonary barotrauma during the decompression process. Our study showed a significant decrease in $\mathrm{FEV}_{1} \%$ over time. Most previous studies also reported $\mathrm{FEV}_{1} \%$ reduction over time in divers, even if there were different patterns of change in $\mathrm{FEV}_{1}$ or FVC $[6,10,18,20,21]$. Change in $\mathrm{FEV}_{1} \%$ in $\mathrm{HIAs}$ was more reduced than the predicted value. It may indicate that HIAs had more risk of airway obstruction than the normal population. We considered that reduction of $\mathrm{FEV}_{1} \%$ was due to the higher density of breathing gas. At depth, the density of pressurized air is higher than breathing gas at surface pressure. This high gas density may increase resistance in the airways causing a decline in $\mathrm{FEV}_{1} \%$. However, there was a term of "pulmonary dysanapsis" in divers [23]. It was a disproportionate growth of $\mathrm{FEV}_{1}$ and vital capacity. This study reported that divers who had a normal $\mathrm{FEV}_{1}$ with a disproportionately large lung capacity had a reduction in $\mathrm{FEV}_{1} / \mathrm{FVC}$ ratio. It seems that our study reported that the rate of reduction in $\mathrm{FEV}_{1}$ was the same as the predicted values while FVC in HIAs did not decrease the same as the normal population. Besides declaring fitness to work in divers and HIAs, diving officers or physicians should observe the trend in changes of these lung function parameters especially $\mathrm{FEV}_{1} \%$.

In previous study, total number of dives, average diving depth and maximal diving depth were important factors associated with change in lung function parameters $[6,8,13,14,17]$. There were three factors in our study that correlated with lung function change consisting of average working depth, average session duration and total working hours. These were similar to the previous studies of Ozdemir et al. [6] and Skogstad et al. [13, 17] who reported that the total number of sessions or number of dives was associated with the reduction of $\mathrm{FEF}_{25 \%}, \mathrm{FEF}_{75 \%}$ and $\mathrm{FEF}_{25-75 \%}$. In contrast with our study, there was no association between $\mathrm{FEF}_{25-75 \%}$ and any hyperbaric exposure. We found that total working hour was associated with change of FVC, percentage predicted of FVC and $\mathrm{FEV}_{1} \%$. Similarly, previous studies in commercial divers showed that the total number of dives was related to changes in $\mathrm{FEV}_{1} \%$ [20] and cumulative diving hours was related to changes in $\mathrm{FEV}_{1}$ and FVC [14]. We also found that average working depth was associated with change in $\mathrm{FEV}_{1}$ and percentage predicted of $\mathrm{FEV}_{1}$. The study of Davey et al. [8] was the only study in commercial divers which reported that maximal depth was related to changes in FVC. In addition, this is the first study that showed that average session duration was correlated with percentage predicted of $\mathrm{FEV}_{1}$.

\section{LIMITATIONS OF THE STUDY}

There are certain limitations to our study. Firstly, lung function parameters in this study are secondary data from medical records. Even with the use of standard operating 
procedures by certified technicians and calibration of spirometers, the quality of lung function test results may vary by medical centres. Secondly, the history of hyperbaric exposure in inside attendants was not documented each year. We collected these data at the date of answering the questionnaire. As a result, recall bias and information bias may be presented in this study.

\section{CONCLUSIONS}

In conclusion, the results indicate that working in a hyperbaric environment affects the lung function of HIAs. Additional to fitness to work implementation, periodic lung function evaluation should be encouraged to monitor further possible harm to the attendants, especially a change of $\mathrm{FEV}_{1} \%$.

\section{ACKNOWLEDGEMENTS}

We thank hyperbaric inside attendants for their participation in this study and Dr. Thanawat Supanitayanon, Dr. Napaporn Sai-ngern, Mr. Ian Michael David Trevallion and Mr. Ponlawit Wisomka for their excellent assistance and support. This study is supported by Graduate School Thesis Grant, Chulalongkorn University.

\section{REFERENCES}

1. Fracica PJ, Knapp MJ, Piantadosi CA, et al. Responses of baboons to prolonged hyperoxia: physiology and qualitative pathology. Journal of Applied Physiology. 1991; 71(6): 2352-2362, doi: 10.1152/ jappl.1991.71.6.2352.

2. Thom SR, Milovanova TN, Bogush M, et al. Microparticle production, neutrophil activation, and intravascular bubbles following open-water SCUBA diving. J Appl Physiol (1985). 2012; 112(8): 1268-1278, doi: 10.1152/japplphysiol.01305.2011, indexed in Pubmed: 22323646.

3. Thom S, Milovanova T, Bogush M, et al. Bubbles, microparticles, and neutrophil activation: changes with exercise level and breathing gas during open-water SCUBA diving. Journal of Applied Physiology. 2013; 114(10): 1396-1405, doi: 10.1152/japplphysiol.00106.2013.

4. Moon RE, Cherry AD, Stolp BW, et al. Pulmonary gas exchange in diving. J Appl Physiol (1985). 2009; 106(2): 668-677, doi: 10.1152/ japplphysiol.91104.2008, indexed in Pubmed: 19008484.

5. Segadal K, Gulsvik A, Nicolaysen G, et al. Respiratory changes with deep diving. Eur Respir J. 1990; 3(1): 101-8.

6. Ozdemir A, Uzun G, Turker T, et al. Changes in pulmonary function in hyperbaric chamber inside attendants: a case-control study. Undersea Hyperb Med. 2016; 43(7): 805-811, indexed in Pubmed: 28777517.

7. Crosbie WA, Clarke MB, Cox RA, et al. Physical characteristics and ventilatory function of 404 commercial divers working in the North Sea. Br J Ind Med. 1977; 34(1): 19-25, doi: 10.1136/oem.34.1.19, indexed in Pubmed: 843459.
8. Davey IS, Cotes JE, Reed JW, et al. Relationship of ventilatory capacity to hyperbaric exposure in divers. J Appl Physiol Respir Environ Exerc Physiol. 1984; 56(6): 1655-1658, doi: 10.1152/ jappl.1984.56.6.1655, indexed in Pubmed: 6735824.

9. Watt SJ. Effect of commercial diving on ventilatory function. Br J Ind Med. 1985; 42(1): 59-62, doi: 10.1136/oem.42.1.59, indexed in Pubmed: 3965017.

10. Thorsen E, Segadal K, Kambestad BK, et al. Pulmonary function one and four years after a deep saturation dive. Scand J Work Environ Health. 1993; 19(2): 115-120, indexed in Pubmed: 8316778.

11. Reuter M, Tetzlaff K, Steffens JC, et al. Functional and high-resolution computed tomographic studies of divers' lungs. Scand J Work Environ Health. 1999; 25(1): 67-74, indexed in Pubmed: 10204673.

12. Skogstad M, Thorsen E, Haldorsen T, et al. Lung function over the first 3 years of a professional diving career. Occup Environ Med. 2000; 57(6): 390-395, doi: 10.1136/oem.57.6.390, indexed in Pubmed: 10810128.

13. Skogstad M, Thorsen E, Haldorsen T, et al. Lung function over six years among professional divers. Occup Environ Med. 2002; 59(9): 629-633, doi: 10.1136/oem.59.9.629, indexed in Pubmed: 12205238.

14. Fitzpatrick DT, Conkin J, Fitzpatrick DT, et al. Improved pulmonary function in working divers breathing nitrox at shallow depths. Aviat Space Environ Med. 2003; 74(7): 763-767, indexed in Pubmed: 12862332.

15. Adir Y, Shupak A, Laor A, et al. Large lungs in divers: natural selection or a training effect? Chest. 2005; 128(1): 224-228, doi: 10.1378/ chest.128.1.224, indexed in Pubmed: 16002939.

16. Tetzlaff K, Theysohn J, Stahl C, et al. Decline of FEV1 in scuba divers. Chest. 2006; 130(1): 238-243, doi: 10.1378/chest.130.1.238, indexed in Pubmed: 16840408.

17. Skogstad M, Skare O, Skogstad M, et al. Pulmonary function among professional divers over 12 years and the effect of total number of dives. Aviat Space Environ Med. 2008; 79(9): 883-887, indexed in Pubmed: 18785357.

18. Chong SiJ, Tan TW, Lim JY, et al. Changes in lung function in Republic of Singapore Navy divers. Diving Hyperb Med. 2008; 38(2): 68-70, indexed in Pubmed: 22692687.

19. Sames C, Gorman DF, Mitchell SJ, et al. The long-term effects of compressed gas diving on lung function in New Zealand occupational divers: a retrospective analysis. Diving Hyperb Med. 2009; 39(3): 133-137, indexed in Pubmed: 22753243.

20. Pougnet R, Anne H, Mialon P, et al. Evolution of the ventilatory function of professional divers over 10 years. Undersea Hyperb Med. 2013; 40(4): 339-43.

21. Voortman M, Ooij PJ, Hulst RA, et al. Pulmonary function changes in Navy divers during their professional careers. Undersea Hyperb Med. 2016; 43(6): 649-657, indexed in Pubmed: 28768392.

22. Dejsomritrutai W, Nana A, Maranetra KN, et al. Reference spirometric values for healthy lifetime nonsmokers in Thailand. J Med Assoc Thai. 2000; 83(5): 457-466, indexed in Pubmed: 10863890.

23. Ong LM, Bennett MH, Thomas PS, et al. Pulmonary dysanapsis and diving assessments. Undersea Hyperb Med. 2009; 36(5): 375-380, indexed in Pubmed: 20112528. 